ROCZNIKI HUMANISTYCZNE

Tom LXIX, zeszyt $12-2021$

DOI: https://doi.org/10.18290/rh216912-4

\title{
MUZYKA INSTRUMENTALNA KAPELI KOŚCIOŁA FARNEGO PW. ŚW. JADWIGI ŚLĄSKIEJ W GRODZISKU WIELKOPOLSKIM
}

\section{WSTĘP}

W osiemnastowiecznej Rzeczpospolitej działało wiele kapel muzycznych przy katedrach, kolegiatach, klasztorach, a także przy miejskich świątyniach parafialnych. Takim przykładem jest kościół pw. Świętej Jadwigi Śląskiej w Grodzisku Wielkopolskim. Choć istnieją wzmianki o działających tam wcześniej muzykach, to jednak ożywienie muzyczne nastąpiło po roku 1710 . W tym mniej więcej czasie swoją działalność rozpoczęła kapela parafialna funkcjonująca aż do połowy XIX wieku (Idaszak, Grodzisk Wielkopolski 14-21).

Jej aktywność dokumentują m.in. muzykalia, których zbiór liczący ok. 720 utworów jest obecnie przechowywany w Archiwum Archidiecezjalnym w Poznaniu. Większość z nich stanowią kościelne dzieła wokalno-instrumentalne (msze, requiem, ofertoria, antyfony maryjne, nieszpory, psalmy, litanie, arie religijne). Jednak wśród nich znajdują się również kompozycje instrumentalne. Problematykę repertuaru instrumentalnego kapel kościelnych poruszali w publikacjach m.in.: B. Stróżyńska, T. Jeż, M. Walter-Mazur, A. Mądry, R. Pośpiech, A. Patalas, M. Jochymczyk, D. Smolarek.

Dr Dariusz Smolarek SAC - Katolicki Uniwersytet Lubelski Jana Pawła II, Instytut Nauk o Sztuce; adres do korespondencji: Al. Racławickie 14, 20-950 Lublin; e-mail: dariusz.smolarek@kul.pl; ORCID: https://orcid.org/0000-0002-8609-8525.

Dr. Dariusz SmolareK SAC, John Paul II Catholic University of Lublin, Institute of Art Studies; address for correspondence: Al. Racławickie 14, 20-950 Lublin, Poland; e-mail: dariusz.smolarek@kul.pl; ORCID: https://orcid.org/0000-0002-8609-8525. 


\section{MUZYKALIA - ILOŚĆ I ZAWARTOŚĆ}

Zbiór liczy 670 jednostek archiwalnych, z czego 42 zawierają muzykę instrumentalną. Wśród nich są rękopisy zbiorcze, które obejmują więcej niż jedną kompozycję. Niewielką część stanowią tylko karty tytułowe albo zapis jednego głosu na końcu utworu wokalno-instrumentalnego.

Zasób utworów instrumentalnych przynależących do parafialnego zbioru z Grodziska Wielkopolskiego liczy 82 pozycje i przedstawia się następująco 40 symfonii, 1 symfonia koncertująca, 1 koncert na róg, 1 uwertura do baletu, 12 duetów instrumentalnych oraz 27 tańców (14 polonezów, 4 walce, 4 kontredanse, 2 mazury, 1 anglese, 1 air, 1 niezidentyfikowany) (Idaszak, Grodzisk Wielkopolski; RISM). Wśród nich znajdują się 52 kompozycje imienne z określoną datą oraz 33 datowane utwory anonimowe. Utwory instrumentalne zapisywano od roku 1760 do ok. 1840.

Ponadto zachowały się stare spisy inwentarza kapeli kościoła grodziskiego, które wymieniają również gatunki muzyki instrumentalnej, a wśród nich: 30 symfonii na 206 utworów (inwentarz z 1853 r.), 34 symfonie i 3 duety skrzypcowe (spis nut w aktach Dekanatu Grodziskiego z 1868 r.), 28 symfonii i koncertów wśród 343 pozycji (inwentarz muzykaliów z 8.07.1888 r.) (Idaszak 21-22, 329). Te informacje pozwalają wysnuć wniosek, że repertuar (nie tylko instrumentalny) był użytkowany jeszcze w II połowie XIX wieku. Z datowania jak i pojawiających się nazwisk kompozytorów wynika, że były to utwory z poprzednich epok: przedklasycznej, klasycyzmu lub wczesnego romantyzmu.

\section{DATOWANIE, KOPIŚCI, POSESORZY}

Najstarsze rękopisy pochodzą z lat sześćdziesiątych i początku siedemdziesiątych XVIII wieku i zawierają symfonie: C. Feyera (18/19 w.) - kopista Maciej Bocheński (1727-1782), J. Namieyskiego (18 w.) - posesor Stanisław Ścigalski, C. F. Abla (1723-1787) i Gaetano († ok. 1792) - kopista A. Fengler (ok. 1745 - 5.11.1786 Grodzisk Wielkopolski), J. Ordentza (18 w.) - kopista M. Bocheński. Znaczną część manuskryptów z muzyką instrumentalną kopiowano w latach 1780-1800. W ich sporządzaniu przodowała rodzina Ścigalskich: Stanisław (ok. 1750 Lwówek - 13.06.1823 Grodzisk Wielkopolski, ojciec muzyków Józefa i Franciszka) - przepisał 13 utworów. Wśród nich są symfonie: A. Dankowskiego, J. Engela, J. Gołąbka, V. Pichla, także Symphonia in D jego syna Franciszka (29.01.1782 Grodzisk Wielkopolski - 27.09.1846 
Gniezno) oraz koncert Es-dur na róg F. Ziegenheima. Józef Ścigalski (27.02.1790 Grodzisk Wielkopolski - 5.12.1841 tamże) sporządził rękopisy z 2 symfoniami E. Eichnera, 1 I. Pleyela i 2 anonimowymi.

Zbiór nut po śp. S. Ścigalskim (director musicae kapeli w Grodzisku od 1780 r.) uporządkował i przekazał chórowi Paweł Sebastian Kinosowicz (1795 Poznań - po 1857 Grodzisk Wielkopolski, pełnił funkcję kapelmistrza i kopisty po Z. Grosmannie). Świadczą o tym inskrypcje, np. „Z Papierów Stanisława Ścigalskiego w Grodzisku”. Czasem dodawał swoje uwagi: „Całe i dobre; W. Pan Józef Ścigalski były kapelmistrz/po zejściu z tego świata ofiarował Kościołowi/Grodziskiemu Parafialnemu/Requiescant in pace/Za zgodność z Oryginałem/Paweł Kinosowicz". Podobne napisy znajdują się m.in. na kartach zbioru 5 symfonii (kolekcja, sygn. Muz GR V/47) z symfoniami E. Eichnera (2), I. Pleyela i Anonimowych (2) i wielu innych (Idaszak, Grodzisk Wielkopolski 297).

Powiązania z muzykami grodziskiej parafii miał radny miejski Ignacy Anastazy Dygasiewicz (1760-?). Dostarczał kapeli nuty, podpisując „Ad usum Chori Parochialis Grodecensis procuravit nobilis Ignatius Dygasiewicz". Z dzieł orkiestrowych ofiarował Symphonie in Dis [ReiE 3] E. Eichnera (Muz GR V/7) i Symphonia in B [SacG 57] F.-J. Gosseca (Muz GR V/12). Prawdopodobnie I. Dygasiewicz utrzymywał kontakty z klasztorem cystersów w niedalekiej Obrze, gdzie przebywał jego brat Tomasz Dygasiewicz SOC (imię zakonne o. Niward), który również dostarczał nuty kapeli muzycznej w Grodzisku. Interesującym jest fakt, że rękopisy sygnowane nazwiskiem I. Dygasiewicza znalazły się w zbiorach muzycznych kapeli cystersów w Krakowie Mogile, m.in. anonimowa Symphonia ex Dis (sygn. 917) Ex rebus Ignatij Dygasiewicz (Smolarek, Kompozytorzy muzyki instrumentalnej 176). Koneksje rodzinne mogły przyczyniać się do wymiany i recepcji repertuaru w różnych ośrodkach muzycznych Rzeczpospolitej.

Kolejny kopista, Zygmunt Stanisław Grosmann (1786 Grodzisk Wielkopolski - 1850 tamże), był kantorem, skrzypkiem, a także kompozytorem. Oprócz twórczości muzyki sakralnej w zbiorze kapeli zachowały się autografy trzech jego duetów skrzypcowych (1815 r.). Jeden z nich dedykował Philipowi de Batthyani (sygn. Muz GR V/1 [1]). Książęta Batthyani byli węgierską rodziną działającą w Cesarstwie Austriackim i może zastanawiać fakt czy Z. Grosmann znał kogoś z tego książęcego rodu. Rękopisy pozostawił również kompozytor A. Dankowski, a także nieznani: Karol Skaÿde, Gärtner (ok. 1791); P. Nierel (fl. 1800); A. Jaskowski (1840). 


\section{KOMPOZYTORZY}

Druga połowa wieku XVIII była okresem rozkwitu twórczości instrumentalnej, a szczególnie orkiestrowej. Swój wkład w rozwój symfonii mieli twórcy działający w szkole mannheimskej, wczesnoklasycznej, klasycznej i wiedeńskiej. Kompozytorzy tworzyli pod wpływem stylu „wzmożonej uczuciowości” („Empfindsamer Still”) oraz „,burzy i naporu” (,Sturm und Drang”). Wiele ówczesnych utworów instrumentalnych znalazło się w repertuarze nie tylko orkiestr królewskich czy książęcych, ale również kościelnych. Także w Polsce zachowały się przekazy muzyki instrumentalnej twórców zagranicznych, których, symfonie mogły być inspiracją dla rodzimych twórców.

Nazwiska kompozytorów symfonii wskazują na dwa kierunki stylistyczne. Jedną grupę stanowią twórcy szkoły mannheimskiej, inną reprezentują dojrzały styl klasyczny. Do pierwszego kręgu należą: Carl Friedrich Abel (22.12.1723 Köthen - 20.06.1787 Londyn), Ernst Dieterich Adolph Eichner (15.02.1740 Arolsen - 1777 Poczdam), Anton Filtz [Antonin Fils, Filz, Fieltz, Fiels] (ochrzcz. 22.09.1733 Eichstätt - 14.03.1760 Mannheim), Carl Stamitz (ochrzcz. 8.05.1745 Mannheim - 9.11.1801 Jena). Styl mannheimski w muzyce francuskiej prezentuje François-Joseph Gossec (17.01.1734 Vergnies 16.02.1829 Passy k. Paryża), a na jego francuską formę symfoniczną wpływała również twórczość klasyków wiedeńskich (Chwedczuk 405).

Dojrzały styl klasyczny reprezentują symfonie Václava Pichla [Venceslaus, Wenzel Pichel] (25.09.1741 Bechyně - 23.01.1805 Wiedeń), Ignacego Pleyela (18.06.1757 Ruppersthal [Dolna Austria] - 14.11.1831 Paryż), Adalberta Gyrowtza [Vojtěch Matyáš Jírovec] (20.02.1763 Czeskie Budziejowice - 19.03.1850 Wiedeń). Natomiast późny styl klasyczny z wpływami romantyzmu znajduje się w twórczości Vaclava Vincenca Maška (5.04.1755 Zvíkovec [okres Rokycany, Plzeňský kraj] - 15.11.1831 Praha) (Československý hudebni slovnik).

W zbiorze grodziskim odnotowano utwory instrumentalne kompozytorów nieznanego pochodzenia: Jan Battista Feger [Feiger] (18/19 w.) [?], Constantin Feyer (18/19), Gaetano († ok. 1792) - Włoch [?], Joannes Ordentz (18 w., pochodzący być może z kręgu niemieckiego [?]), Franz Ziegenheim (18.sc) [?], którego kilka kompozycji sakralnych znajduje się w polskich archiwach (mógł pochodzić z Austrii lub Czech).

„Symfonia, jako główny gatunek muzyczny obok koncertu instrumentalnego w XVIII wieku opanował szerokie spektrum życia społecznego - od domów prywatnych mieszczańskich, przez dwory, sale koncertowe, uroczystości państwowe, aż po kościoły" (Mądry 607). W osiemnastowiecznej Polsce pokaźną rolę w rozpowszechnianiu tego gatunku odgrywały ośrodki kościelne. 
Symfonie służyły nie tylko prezentacji podczas specjalnych koncertów, ale również oprawie nabożeństw w kościele, np. rozpoczęcie i zakończenie celebracji eucharystycznej, zastępowanie zmiennych części mszy (offertorium, communio). Był to więc typ symfonii kościelnej, które komponowano dla lokalnych kapel kościelnych. Nie można ich porównywać do symfonii powstających w tym czasie w największych ośrodkach europejskich (Mądry 607). W rodzimych zbiorach po kapelach kościelnych (m.in. grodziska) zachowały się symfonie obcych kompozytorów z wyżej wymienionych szkół. Świadczy to o tym, że kapelmistrze dbali, aby miejscowa ludność miała kontakt z kulturą europejską. $Z$ drugiej zaś strony lokalni kompozytorzy czerpali wzorce do swoich symfonii, które wykonywano najczęściej w kościele (o symfonii w kontekście kościelnym, zob. Stróżyńska 319-41).

Wyżej przedstawiona sytuacja dotyczy również grodziskiego repertuaru symfonii, których autorami są następujący rodzimi kompozytorzy:

- Wojciech Dankowski [Adalbertus Danek] (ok. 1760 - po 1800) działający w Wielkopolsce jest przedstawicielem wczesnego klasycyzmu, nawiązującego do stylu muzyki baroku, jak i klasyków wiedeńskich w zakresie budowy formy sonatowej, struktury tematu, traktowaniu partii basowej (bc) oraz użycia elementów stylu galant w powolnych częściach utworów (Idaszak, Dankowski 339);

- Jakub Gołąbek (1739 - 30.03.1789 Kraków), śpiewak i kompozytor kapeli katedralnej na Wawelu, którego utwory posiadają wiele cech wspólnych z wczesnym klasycyzmem (Mądry 618-19);

- Antoni Habel (1760 Gniezno - 6.10.1831 tamże), muzyk katedry w Gnieźnie komponującego w stylu klasycznym („Habel Antoni” 4);

- Jan Engel († 30.06.1788), który w swoich symfoniach w stylu przedklasycznym nawiązywał do 3 częściowej uwertury neapolitańskiej stosując zwroty melodyczno-rytmiczne zaczerpnięte z rodzimej muzyki ludowej (Stróżyńska, broszura CD);

- Franciszek Ścigalski (29.01.1782 Grodzisk Wielkopolski - 27.08/09.1846 Gniezno), twórca dojrzałego klasycyzmu stosujący motywy poloneza (ChmaraŻaczkiewicz 302-3);

- Jan Namieyski (18 w.), którego jedyna zachowana 5 częściowa symfonia (drugi egzemplarz na Jasnej Górze) nawiązuje do rytmów polonezowych, a elementy bliskie klasycyzmowi wzbogacał rodzimą muzyką ludową (Stróżyńska, broszura CD);

- Karol Pietrowski (II poł. XVIII w.), mało znany polski kompozytor działający prawdopodobnie w Wielkopolsce, który wzorował się na muzyce J. Haydna i W. A. Mozarta (Duszyk 107). 
Oprócz symfonii w zbiorze grodziskim zachowały się inne kompozycje instrumentalne. Jedną z nich jest aranżacja popularnej arii „Non più andrai” $\mathrm{z}$ opery Le Nozze di Figaro (KV 492)] W. A. Mozarta (27.01.1756 Salzburg 4.12.1791 Wiedeń) (Mądry, 663-65). Również fragmenty Ouverture. Z Baletu Rendez komicznego nieznanego Wursta (18/19) wskazują na zainteresowania muzyków kapeli parafialnej twórczością świecką.

W repertuarze znalazły się duety instrumentalne kompozytorów z przełomu XVIII i XIX w. będących przedstawicieli francuskiej szkoły skrzypcowej: Josepha Gravranda l'aîne (1770-1847) i Charles-Frédéric Kreubé (1777-1846). Kolejnymi są trzy duety skrzypcowe I. Pleyela. Zbiór zawiera duet Charles-Auguste de Bériota (1802-1870), który dał podwaliny nowoczesnej francusko-belgijskiej szkole gry skrzypcowej (napisał podręcznik Methode de violin..., a do jego uczniów należał sławny skrzypek Henri Vieuxtemps, 1820-1881) (Bula 284).

Duety instrumentalne gromadził i komponował Zygmunt Stanisław Grosman (1786-1850) zapewne dla użytku osobistego jak i swoich synów muzyków: Maksymiliana Gerarda (1808-1832), Adama Stefana (1810-1839), Jana Walentego (1824-1853) (Idaszak 294). Prawdopodobnie znajomość symfonii działających we Francji Gosseca i Pleyela mogła przyczynić się do zetknięcia z utworami francuskich skrzypków - kompozytorów. Włoską szkołę skrzypcową reprezentują wydane drukiem kompozycje Bartolomeo Campagnoli (10.09.1751 Cento di Ferrara - 6.11.1827 w Neustrelitz Niemcy). Duety skrzypcowe służyły prawdopodobnie do ćwiczenia lub domowego muzykowania.

W zbiorze muzykaliów znajdują się ponadto 3 symfonie anonimowe oraz fragmenty kilkunastu tańców: m.in. 14 polonezów, 4 walców. Prawdopodobnie te ostatnie mogły służyć muzykom podczas uroczystości świeckich lub zabaw.

Należące do repertuaru kapeli kościelnej Grodziska Wielkopolskiego utwory instrumentalne przynależą do różnych tendencji stylistycznych. Warto przy tym zauważyć twórców polskich, których symfonie w tym ośrodku były niemniej popularne niż obce. Również w twórczości kompozytorów rodzimych można zauważyć różne kierunki stylistyczne: od galant (W. Dankowski) poprzez przedklasyczny (J. Engel) i wczesny klasycyzm (J. Gołąbek, W. Dankowski) po klasyczny (W. Dankowski, A. Habel, F. Ścigalski, K. Pietrowski). W symfoniach niektórych z nich jest zauważalny wpływ wielu prądów muzyki XVIII wieku (np. W. Dankowski). Jednak europejskie tendencje w utworach naszych kompozytorów objawiają się z pewnym opóźnieniem w stosunku do twórców zagranicznych, choć nie jest to trend w kierunku tylko naśladowczym. Przykładem tego są symfonie z elementami melodyczno-rytmicznymi polskich tańców, a szczególnie poloneza (J. Namieyski, F. Ścigalski). 


\section{RECEPCJA REPERTUARU INSTRUMENTALNEGO}

Odpisy niektórych zachowanych symfonii znajdują się w innych ośrodkach kościelnych i zostaną przedstawione w ten sposób, że po sygnaturze ze zbioru z Grodziska Wielkopolskiego podano oznaczenie archiwum i numer sygnatury rękopisu:

- C. F. Abel, Symfonia C-dur op. 7 nr 5; KnaA 17, Muz GR V/46 - PL-CZ III-833,

- C. F. Abel, Symfonia D-dur; KnaA 12, Muz GR V/6 - PL-GD Ms 4258 IV,

- C. F. Abel, Symfonia F-dur op. 7 nr 4; KnaA 16, Muz GR V/5 - PL-MO, sygn. 948 ,

- C. F. Abel, Symfonia Es-dur op. 7 nr 6; KnaA 18, Muz GR V/4 - PL-STAb 9d,

- W. Dankowski, Symfonia Es-dur, Muz GR V/48 - PL-GNd Muz VI 9,

- J. Engel, Symfonia D-dur, Muz GR V/15 - PL-CZ III-325,

- J. Gołąbek, Symfonia D-dur - PL-MO, sygn. 938, PL-CZ III 277,

- Habel, Symfonia D-dur, Muz GR V/44 - PL-GNd VI/8,

- J. Namieyski, Symfonia D-dur, Muz GR V/35 - PL-CZ III-323,

- V. Pichl, Symfonia G-dur; ZakP 22, Muz GR V/19 - PL-Stab 21d.

Z zestawienia wynika, że w klasztorze oo. Paulinów na Jasnej Górze znajdują się odpisy czterech symfonii; u sióstr Benedyktynek w Staniątkach i w Archiwum Archidiecezjalnym w Gnieźnie 2, u cystersów w Mogile 1. Z 40 zachowanych symfonii z Grodziska Wielkopolskiego, 9 znalazło się w innych ośrodkach, z tego 5 autorstwa polskich kompozytorów. Fakt ten świadczy o popularności tego gatunku wśród muzyków kapel kościelnych.

Zasób muzyki instrumentalnej znajdującej się w zbiorze muzykaliów po kapeli kościoła farnego w Grodzisku Wielkopolskim zostanie przedstawiony za pomocą zestawienia tabelarycznego. Pierwsza tabela będzie zawierała dzieła orkiestrowe (symfonie, symfonia koncertująca, koncert). Drugi wykaz jest rejestrem duetów instrumentalnych. W trzeciej tabeli znajdzie się zestawienie kompozycji, które w rękopisach noszą nazwę tańców. Tytuł kompozycji, skróty nazw instrumentów i ogólnego datowania przyjęto wg standardów RISM.

Kolumny tabeli zawierają następujące informacje:

- Kompozytor: nazwisko (alfabetycznie) i imię kompozytora i lata życia (domniemanego w nawiasie [ ] na podstawie konkordancji w bazie RISM). 
- Tytuł: oryginalna nazwa kompozycji zapisana na karcie tytułowej lub w nagłówku. W nawiasie [ ] uzupełnienie tonacji, tytułu, numeru w katalogu dzieł kompozytora.

- Części (tonacja, metrum): nazwy części utworu wraz z tonacją i metrum.

- Obsada: wykaz instrumentów (również z zaginionych kart) danej kompozycji.

- Data, kopista, posesor: czas ukończenia odpisu, nazwisko (inicjał) skryptora lub posesora. Wszystkie muzykalia posiadają proweniencję: Kościół farny pw. św. Jadwigi Śląskiej, Kościelna 1, 62-065 Grodzisk Wielkopolski.

- Sygnatura: oznaczenie rękopisu znajdującego się w Archiwum Archidiecezjalnym, ul. Ks. Ignacego Posadzego 2, 61-108 Poznań. Niekiedy dana jednostka może zawierać więcej utworów (tzw. rękopis zbiorczy); liczba w nawiasie ( ) oznacza numer w katalogu D. Idaszak (Idaszak, Grodzisk Wielkopolski).

Tabela 1. Symfonie

\begin{tabular}{|c|c|c|c|c|c|c|}
\hline & Kompozytor & Tytul & $\begin{array}{l}\text { Części } \\
\text { (tonacja } \\
\text { metrum) }\end{array}$ & Obsada & $\begin{array}{l}\text { Data, } \\
\text { kopista, } \\
\text { posesor }\end{array}$ & Sygnatura \\
\hline 1 & $\begin{array}{l}\text { Abel Carl } \\
\text { Friedrich } \\
(1723-1787)\end{array}$ & $\begin{array}{l}\text { Symphonie } \\
\text { in } C \text { [KnaA 17] }\end{array}$ & $\begin{array}{l}\text { Allegro }(\mathrm{C} ; 4 / 4) \\
\text { Andante }(\mathrm{F} ; 3 / 8) \\
\text { Prestissimo } \\
(\mathrm{C} ; 2 / 4)\end{array}$ & $\begin{array}{l}\text { vl (2), a-vla, b, } \\
\text { ob (2), cor (2) }\end{array}$ & 1770 & $\begin{array}{l}\text { Muz GR } \\
\text { V/46 (2) }\end{array}$ \\
\hline 2 & $\begin{array}{l}\text { Abel Carl } \\
\text { Friedrich }\end{array}$ & $\begin{array}{l}\text { Sinfonia ex D } \\
{[\text { KnaA 12] }}\end{array}$ & $\begin{array}{l}\text { Allegro (D; 4/4) } \\
\text { Andante (G; } 2 / 4) \\
\text { Presto (D ; 3/8 }\end{array}$ & $\begin{array}{l}\text { vl (2), a-vla, b, } \\
\text { ob (2), cor (2) }\end{array}$ & $\begin{array}{c}\text { 1768, Antoni } \\
\text { Fengler }\end{array}$ & $\begin{array}{c}\text { Muz GR } \\
\text { V/6 (3) }\end{array}$ \\
\hline 3 & $\begin{array}{l}\text { Abel Carl } \\
\text { Friedrich }\end{array}$ & $\begin{array}{l}\text { Symphonia } \\
\text { in } F \text { [KnaA 16] }\end{array}$ & $\begin{array}{l}\text { Allegro }(\mathrm{F} ; 4 / 4) \\
\text { Andante }(\mathrm{B} ; 3 / 4) \\
\text { Tempo di minuetto } \\
(\mathrm{F} ; 3 / 4)\end{array}$ & $\begin{array}{l}\text { vl (2), a-vla, b, } \\
\text { ob (2), cor (2) }\end{array}$ & ok. 1790 & $\begin{array}{c}\text { Muz GR } \\
\text { V/5 (4) }\end{array}$ \\
\hline 4 & $\begin{array}{l}\text { Abel Carl } \\
\text { Friedrich }\end{array}$ & $\begin{array}{l}\text { Symphonia } \\
\text { in Dis } \\
{[\text { KnaA 18] }}\end{array}$ & $\begin{array}{l}\text { Allegro (Es; 4/4) } \\
\text { Andante (c; } 2 / 4) \\
\text { Finale. Allegro } \\
\text { assai (Es; } 3 / 8)\end{array}$ & $\begin{array}{l}\text { vl (2), a-vla, b, } \\
\text { ob (2), cor (2) }\end{array}$ & ok. 1790 & $\begin{array}{c}\text { Muz GR } \\
\text { V/4 (5) }\end{array}$ \\
\hline 5 & $\begin{array}{c}\text { Dankowski } \\
\text { Adalbert } \\
\text { [Danek, } \\
\text { Wojciech] } \\
\text { (ok. 1760-1814) }\end{array}$ & Synphonia in D & & $\begin{array}{l}\mathrm{vl}(2), \mathrm{a}-\mathrm{vla}, \mathrm{b}, \\
\mathrm{fl}(2), \operatorname{cor}(2)\end{array}$ & \begin{tabular}{|} 
ok. 1780, \\
Stanisław \\
Ścigalski \\
[Tylko \\
k. tytułowa]
\end{tabular} & $\begin{array}{l}\text { Muz GR } \\
\text { V/31 (66) }\end{array}$ \\
\hline
\end{tabular}




\begin{tabular}{|c|c|c|c|c|c|c|}
\hline & Kompozytor & Tytul & $\begin{array}{c}\text { Części } \\
\text { (tonacja } \\
\text { metrum) }\end{array}$ & Obsada & $\begin{array}{l}\text { Data, } \\
\text { kopista, } \\
\text { posesor }\end{array}$ & Sygnatura \\
\hline 6 & $\begin{array}{l}\text { Dankowski } \\
\text { Adalbert }\end{array}$ & $\begin{array}{l}\text { Symphonia in } \\
\text { Es }\end{array}$ & $\begin{array}{l}\text { Allegro molto (Es; } \\
\text { 3/4) } \\
\text { Andante (Es; 3/4) } \\
\text { Menuet (Es; 3/4) } \\
\text { Rondo (Es; 3/4) }\end{array}$ & $\begin{array}{l}\text { vl (2), vla, b, } \\
\text { cl (2), fag solo } \\
\text { (dodany), } \\
\text { cor (2) }\end{array}$ & $\begin{array}{l}\text { ok. 1790, S. } \\
\text { Ścigalski, } \\
\text { Paweł } \\
\text { Sebastian } \\
\text { Kinosowicz }\end{array}$ & $\begin{array}{c}\text { Muz GR } \\
\text { V/48 (67) }\end{array}$ \\
\hline 7 & $\begin{array}{c}\text { Eichner, } \\
\text { Ernst (1740- } \\
\text { 1777) }\end{array}$ & $\begin{array}{l}\text { Simphonia } \\
\text { [Es] [ReiE 22] }\end{array}$ & $\begin{array}{l}\text { Allegro (Es; 4/4) } \\
\text { Andante (g; } 2 / 4) \\
\text { Allegro assai (Es; } \\
2 / 4)\end{array}$ & $\begin{array}{l}\mathrm{vl}(2), \mathrm{a}-\mathrm{vla}, \\
\mathrm{fl}(2), \operatorname{cor}(2), \\
\text { org }\end{array}$ & $\begin{array}{c}\text { ok. } 1780 \\
\text { (rps zb.), } \\
\text { Józef } \\
\text { Ścigalski, } \\
\text { P. S. } \\
\text { Kinosowicz }\end{array}$ & $\begin{array}{c}\text { Muz GR } \\
\text { V/47 [1] } \\
(114)\end{array}$ \\
\hline 8 & Eichner, Ernst & $\begin{array}{l}\text { Simphonia }[\mathrm{D}] \\
{[\text { ReiE 23] }}\end{array}$ & $\begin{array}{l}\text { Allegro (D; 4/4) } \\
\text { Andante (A; 3/8) } \\
\text { Allegro (D; } 2 / 4)\end{array}$ & $\begin{array}{l}\text { vl (2), a-vla, } \\
\text { fl (2), cor (2), } \\
\text { org }\end{array}$ & $\begin{array}{l}\text { ok. } 1780 \\
\text { (rps zb.), } \\
\text { J. Ścigalski, } \\
\text { P. S. } \\
\text { Kinosowicz }\end{array}$ & $\begin{array}{c}\text { Muz GR } \\
\text { V/47 [3] } \\
(111)\end{array}$ \\
\hline 9 & Eichner, Ernst & $\begin{array}{l}\text { Sinfonia Ex D } \\
{[\text { ReiE 17] }}\end{array}$ & $\begin{array}{l}\text { Allegro (D; 4/4) } \\
\text { Andante poco } \\
\text { allegro (A; } 2 / 4) \\
\text { Allegro (D; } 2 / 4)\end{array}$ & $\begin{array}{l}\text { vl (2), a-vla, b, } \\
\text { fl lub ob (2), } \\
\text { cor (2) }\end{array}$ & $\begin{array}{l}\text { ok. 1785, } \\
\text { „B. K.” }\end{array}$ & $\begin{array}{c}\text { Muz GR } \\
\text { V/8 (112) }\end{array}$ \\
\hline 10 & Eichner, Ernst & $\begin{array}{l}\text { Symphonie in } \\
\text { Dis [ReiE 3] }\end{array}$ & $\begin{array}{l}\text { Adagio (Es; c/) } \\
\text { Andante (B; 2/4) } \\
\text { Prestissimo } \\
(\text { Es; 3/8) }\end{array}$ & $\begin{array}{l}\text { vl (2), a-vla, } \\
\text { v-lne, fl (2), } \\
\text { cor (2) }\end{array}$ & $\begin{array}{c}\text { ok. 1790, } \\
\text { Ignacy } \\
\text { Anastazy } \\
\text { Dygasiewicz }\end{array}$ & $\begin{array}{c}\text { Muz GR } \\
\text { V/7 (113) }\end{array}$ \\
\hline 11 & $\begin{array}{c}\text { Engel Jan } \\
(† \text { 1788) } \\
{[\text { J. Hayden?] }}\end{array}$ & [Symfonia D] & $\begin{array}{l}\text { Allegro assai (D; } \\
\text { 4/4) } \\
\text { Andante }(d ; 2 / 4) \\
\text { Presto }(D ; 3 / 8)\end{array}$ & $\begin{array}{l}\text { vl (2), a-vla, b, } \\
\text { fl (2) albo } \\
\text { cl (2), cor (2) }\end{array}$ & $\begin{array}{c}\text { Ok. } 1800 \\
\text { (rps zb.), } \\
\text { St. Ścigalski }\end{array}$ & $\begin{array}{c}\text { Muz GR } \\
\text { V/15 [1] } \\
(119)\end{array}$ \\
\hline 12 & Engel Jan & [Symfonia G] & $\begin{array}{l}\text { Allegro assai } \\
(\mathrm{G} ; 4 / 4) \\
\text { Andante }(\mathrm{C} ; 3 / 8) \\
\text { Presto }(\mathrm{G} ; 3 / 8)\end{array}$ & $\begin{array}{l}\text { vl (2), a-vla, b, } \\
\text { fl (2) albo } \\
\text { cl (2), cor (2) }\end{array}$ & $\begin{array}{l}\text { ok. } 1800 \\
\text { (rps zb.), } \\
\text { S. Ścigalski }\end{array}$ & $\begin{array}{c}\text { Muz GR } \\
\text { V/15 [2] } \\
(120)\end{array}$ \\
\hline 13 & Engel Jan & [Symfonia Es] & $\begin{array}{l}\text { Allegro assai } \\
\text { (Es; 4/4) } \\
\text { Andante (c; } 2 / 4) \\
\text { Allegro (Es; 3/8) }\end{array}$ & $\begin{array}{l}\text { vl (2), a-vla, b, } \\
\text { fl (2) albo } \\
\operatorname{cl}(2), \text { cor (2) }\end{array}$ & $\begin{array}{l}\text { ok. } 1800 \\
\text { (rps zb.), } \\
\text { S. Ścigalski }\end{array}$ & $\begin{array}{c}\text { Muz GR } \\
\text { V/15 [3] } \\
(121)\end{array}$ \\
\hline
\end{tabular}




\begin{tabular}{|c|c|c|c|c|c|c|}
\hline & Kompozytor & Tytul & $\begin{array}{c}\text { Części } \\
\text { (tonacja } \\
\text { metrum) }\end{array}$ & Obsada & $\begin{array}{l}\text { Data, } \\
\text { kopista, } \\
\text { posesor }\end{array}$ & Sygnatura \\
\hline 14 & Engel Jan & [Symfonia B] & $\begin{array}{l}\text { Allegro assai } \\
(\mathrm{B} ; 3 / 4) \\
\text { Andante }(\mathrm{Es} ; 2 / 4) \\
\text { Presto }(\mathrm{B} ; 3 / 8)\end{array}$ & $\begin{array}{l}\text { vl (2), a-vla, b, } \\
\text { fl (2) albo } \\
\text { cl (2), cor (2) }\end{array}$ & $\begin{array}{l}\text { Ok. } 1800 \\
\text { (rps zb.), } \\
\text { S. Ścigalski }\end{array}$ & $\begin{array}{c}\text { Muz GR } \\
\text { V/15 [4] } \\
(122)\end{array}$ \\
\hline 15 & $\begin{array}{c}\text { Feger [Feiger] } \\
\text { Jan Battista } \\
(18 / 19 \text { w. })\end{array}$ & $\begin{array}{l}\text { Symphonia } \\
\text { ex } D\end{array}$ & $\begin{array}{l}\text { Allegro (D; 4/4) } \\
\text { Andante con } \\
\text { sordini (G; 3/4) } \\
\text { Menuetto (D; 3/4) } \\
\text { Presto (D; 3/8) }\end{array}$ & $\begin{array}{l}\text { vl (2) a-vla, b, } \\
\text { fl (2) cor (2), } \\
\text { vl (2) a-vla, b, } \\
\text { ob (2) cor (2) }\end{array}$ & $\begin{array}{l}\text { ok. } 1770 \\
\text { ok. } 1780\end{array}$ & $\begin{array}{c}\text { Muz GR } \\
\text { V/49 (603) } \\
\text { Muz GR } \\
\text { V/10 (126) }\end{array}$ \\
\hline 16 & $\begin{array}{c}\text { Feyer } \\
\text { Constantin } \\
(18 / 19)\end{array}$ & Sinfonia ex $C$ & $\begin{array}{l}\text { Allegro assai } \\
(\mathrm{C} ; 4 / 4) \\
\text { Andante (c; } 3 / 4) \\
\text { Presto assai }(\mathrm{C} ; \\
3 / 8)\end{array}$ & $\begin{array}{l}\text { vl (2) a-vla, b, } \\
\text { ob (2) cor (2) }\end{array}$ & $\begin{array}{c}\text { ok. 1760, } \\
\text { Maciej } \\
\text { Bocheński } \\
(1727-1782)\end{array}$ & $\begin{array}{l}\text { Muz GR V/9 } \\
(128)\end{array}$ \\
\hline 17 & $\begin{array}{l}\text { Fils Anton } \\
(1733-1760)\end{array}$ & Sinfonia ex $C$ & $\begin{array}{l}\text { Allegro assai } \\
(\mathrm{C} ; 4 / 4) \\
\text { Andante }(\mathrm{G} ; 2 / 4) \\
\text { Minuetto }(\mathrm{C} ; 3 / 4) \\
\text { Presto }(\mathrm{C} ; 3 / 8)\end{array}$ & $\begin{array}{l}\text { vl (2), vla, b, } \\
\text { ob (2) clno (2), } \\
\text { timp }\end{array}$ & ok. 1770 & $\begin{array}{c}\text { Muz GR } \\
\text { V/11 (129) }\end{array}$ \\
\hline 18 & $\begin{array}{l}\text { Fils Anton } \\
(1733-1760)\end{array}$ & Sinphonia in D & $\begin{array}{l}\text { Allegro (D; 4/4) } \\
\text { Andante (d; 2/4) } \\
\text { Menuet (D; 3/4) } \\
\text { Allegro (D; } 2 / 4)\end{array}$ & $\begin{array}{l}\text { vl (2), vla, b, } \\
\text { fl (2), cor (2), } \\
\text { clno (2) }\end{array}$ & $\begin{array}{c}\text { ok. 1780, } \\
\text { Adalbert } \\
\text { Dankowski } \\
\text { [Danek], } \\
\text { P. S. } \\
\text { Kinosowicz }\end{array}$ & $\begin{array}{c}\text { Muz GR } \\
\text { V/40 (130) }\end{array}$ \\
\hline 19 & $\begin{array}{c}\text { Gaetano } \\
(† \text { ok. 1792) }\end{array}$ & $\begin{array}{l}\text { Symphoniae } \\
\text { Ex Dis }\end{array}$ & $\begin{array}{l}\text { Allegro (Es; } 3 / 4) \\
\text { Andante a mezza } \\
\text { voce ma con } \\
\text { espressione }(g ; 4 / 4) \\
\text { Menuet }(E s ; 3 / 4) \\
\text { Presto }(E s ; c /)\end{array}$ & $\begin{array}{l}\text { vl (2), vla, b, } \\
\text { fl (2), cor in } \\
\text { Es (2), cl (2), } \\
\text { dodany ob (2) }\end{array}$ & $\begin{array}{c}\text { 1768, } \\
\text { Fengler } \\
\text { Antoni (ok. } \\
\text { 1745-1786) }\end{array}$ & $\begin{array}{c}\text { Muz GR } \\
\text { V/37 (605) }\end{array}$ \\
\hline 20 & $\begin{array}{c}\text { Goląbek } \\
\text { Jakub } \\
\text { (1739-1789) }\end{array}$ & $\begin{array}{l}\text { Symphonia } \\
\text { in D }\end{array}$ & $\begin{array}{l}\text { Allegro (D; 4/4) } \\
\text { Rondeau. Andante } \\
(\mathrm{G} ; 22 / 4) \\
\text { Allegro molto } \\
(\mathrm{D} ; 4 / 4)\end{array}$ & $\begin{array}{l}\text { vl (2), vla, b, } \\
\text { ob (2), cor (2) }\end{array}$ & $\begin{array}{l}1780, \\
\text { S. Ścigalski, } \\
\text { P. S. } \\
\text { Kinosowicz }\end{array}$ & $\begin{array}{c}\text { Bez } \\
\text { sygnatury } \\
(134)\end{array}$ \\
\hline
\end{tabular}




\begin{tabular}{|c|c|c|c|c|c|c|}
\hline & Kompozytor & Tytul & $\begin{array}{c}\text { Części } \\
\text { (tonacja } \\
\text { metrum) }\end{array}$ & Obsada & $\begin{array}{l}\text { Data, } \\
\text { kopista, } \\
\text { posesor }\end{array}$ & Sygnatura \\
\hline 21 & $\begin{array}{c}\text { Gossec } \\
\text { François- } \\
\text { Joseph } \\
(1734-1829)\end{array}$ & $\begin{array}{l}\text { Symphonia in } \\
B \text { [SacG 57] }\end{array}$ & $\begin{array}{l}\text { Allegro molto } \\
(\mathrm{B} ; 4 / 4) \\
\text { Lentement ou } \\
\text { largo (Es; 4/4) } \\
\text { Allegro ballabile } \\
(\mathrm{B} ; 2 / 4)\end{array}$ & $\begin{array}{l}\text { vl (2), vla, b, } \\
\text { ob (2), cor (2) }\end{array}$ & \begin{tabular}{|c|} 
ok. 1790, \\
I. \\
Dygasiewicz
\end{tabular} & $\begin{array}{c}\text { Muz GR } \\
\text { V/12 (135) }\end{array}$ \\
\hline 22 & $\begin{array}{c}\text { Habel Antoni } \\
\text { (1760-1831) }\end{array}$ & Sinfonia in D & & $\begin{array}{l}\mathrm{vl}(2), \mathrm{a}-\mathrm{vla}, \mathrm{b}, \\
\mathrm{fl}(2), \operatorname{cor}(2)\end{array}$ & $\begin{array}{c}\text { ok. } 1800, \\
\text { tylko k. } \\
\text { tytułowa }\end{array}$ & $\begin{array}{c}\text { Muz GR } \\
\text { V/14 (172) }\end{array}$ \\
\hline 23 & Habel, Antoni & Symphonia [D] & $\begin{array}{l}\text { Allegro vivace } \\
(\mathrm{D} ; 3 / 4) \text { Andante } \\
\text { cantabile con } 3 \\
\text { variazioni }(\mathrm{A} ; 2 / 4) \\
\text { Menuetto. Allegro } \\
\text { molto }(\mathrm{e} ; 2 / 4) \\
\text { Finale. Allegro } \\
(\mathrm{D} ; 2 / 4)\end{array}$ & $\begin{array}{l}\text { vl (2), a-vla, b, } \\
\text { fl (2), cor (2) }\end{array}$ & $\begin{array}{l}\text { ok. 1780, } \\
\text { P. S. } \\
\text { Kinosowicz }\end{array}$ & $\begin{array}{c}\text { Muz GR } \\
\text { V/44 (173) }\end{array}$ \\
\hline 24 & $\begin{array}{c}\text { Mašek } \\
\text { Vincenc } \\
(\mathbf{1 7 5 5 - 1 8 3 1 )}\end{array}$ & Sinfonia $C$ & $\begin{array}{l}\text { Allegro moderato } \\
(\mathrm{C} ; 3 / 4) \\
\text { Andante con } \\
\text { sordini }(\mathrm{F} ; 4 / 4) \\
\text { Menuetto }(\mathrm{C} ; 3 / 4) \\
\text { Finale. Allegro } \\
(\mathrm{C} ; 2 / 4)\end{array}$ & $\begin{array}{l}\mathrm{vl}(2), \mathrm{a}-\mathrm{vla}, \mathrm{b}, \\
\mathrm{fl}(2), \operatorname{cor}(2)\end{array}$ & $\begin{array}{c}\text { ok. } 1780, \\
\text { Gärtner [?] } \\
\text { Skaÿde } \\
\text { Karol (18.sc) }\end{array}$ & $\begin{array}{c}\text { Muz GR } \\
\text { V/16 (229) }\end{array}$ \\
\hline 25 & $\begin{array}{c}\text { Mozart } \\
\text { Wolfgang } \\
\text { Amadeusz } \\
\text { (1756-1791) } \\
\text { Oprac. } \\
\text { [Rochus] } \\
\text { Pompernicus }\end{array}$ & $\begin{array}{l}\text { Symfonia }[\mathrm{C}] \\
\text { [Aranżacja arii } \\
\text { „Non più } \\
\text { andrai” } \\
\text { z opery Le } \\
\text { Nozze di } \\
\text { Figaro } \\
\text { (KV 492)] }\end{array}$ & Allegro $(C ; 4 / 4)$ & $\begin{array}{l}\text { vl (2), b, fl, } \\
\text { ob (2), cor (2), } \\
\text { timp }\end{array}$ & $\begin{array}{c}\text { ok. 1790, } \\
\text { P. } \\
\text { Kinosowicz }\end{array}$ & $\begin{array}{c}\text { Muz GR } \\
\text { V/17 (234) }\end{array}$ \\
\hline 26 & $\begin{array}{l}\text { Namieyski } \\
\text { Jan (18 w.) }\end{array}$ & $\begin{array}{l}\text { Symphonia } \\
\text { in D }\end{array}$ & $\begin{array}{l}\text { Moderato (D; 4/4) } \\
\text { Menuetto (D; 3/4) } \\
\text { Thema con } 4 \\
\text { variazionni. } \\
\text { Adagio (D; } 2 / 4) \\
\text { Menuetto. } \\
\text { Allegretto (D; 3/4) } \\
\text { Allegro (D; 4/4) }\end{array}$ & $\begin{array}{l}\text { vl (2), a-vla, b, } \\
\text { fl (2), cl (2), } \\
\operatorname{cor}(2)\end{array}$ & $\begin{array}{l}\text { ok. 1760, } \\
\text { S. Ścigalski, } \\
\text { P. S. } \\
\text { Kinosowicz }\end{array}$ & $\begin{array}{c}\text { Muz GR } \\
\text { V/35 (240) }\end{array}$ \\
\hline
\end{tabular}




\begin{tabular}{|c|c|c|c|c|c|c|}
\hline & Kompozytor & Tytul & $\begin{array}{c}\text { Części } \\
\text { (tonacja } \\
\text { metrum) }\end{array}$ & Obsada & $\begin{array}{l}\text { Data, } \\
\text { kopista, } \\
\text { posesor }\end{array}$ & Sygnatura \\
\hline 27 & $\begin{array}{c}\text { Ordentz } \\
\text { Joannes } \\
(18 \text { w. })\end{array}$ & $\begin{array}{l}\text { Symphonia } \\
\text { in F }\end{array}$ & $\begin{array}{l}\text { Allegro (F; 4/4) } \\
\text { Andante (F; 2/4) } \\
\text { Presto (F; 3/8) }\end{array}$ & $\begin{array}{l}\text { vl (2), vla, b, } \\
\text { ob (2), cor (2) }\end{array}$ & $\begin{array}{l}\text { ok. } 1770, \\
\text { M. } \\
\text { Bocheński }\end{array}$ & $\begin{array}{c}\text { Muz GR } \\
\text { V/18 (251) }\end{array}$ \\
\hline 28 & $\begin{array}{l}\text { Pichl [Pichel] } \\
\text { Václav } \\
\text { [Venceslaus, } \\
\text { Wenzel] } \\
\text { (1741-1805) }\end{array}$ & $\begin{array}{l}\text { Symphonia }[\mathrm{G}] \\
{[\text { ZakP 22] }}\end{array}$ & $\begin{array}{l}\text { Allegro (G; 4/4) } \\
\text { Larghetto (e; 3/4) } \\
\text { Rondo. Allegro } \\
(\mathrm{G} ; 2 / 4)\end{array}$ & $\begin{array}{l}\text { vl (2), a-vla, b, } \\
\text { fl (2), cor (2) }\end{array}$ & $\begin{array}{l}1784, \\
\text { S. Ścigalski, } \\
\quad \text { P. S. } \\
\text { Kinosowicz }\end{array}$ & $\begin{array}{c}\text { Muz GR } \\
\text { V/19 (254) }\end{array}$ \\
\hline 29 & $\begin{array}{l}\text { Pietrowski, } \\
\text { Karol } \\
(18 / 19 \text { w. })\end{array}$ & Sinfonia $[\mathrm{D}]$ & $\begin{array}{l}\text { Grave }(\mathrm{D} ; 4 / 4) \\
\text { Andante }(\mathrm{G} ; 2 / 4) \\
\text { Menuetto }(\mathrm{A} ; 3 / 4) \\
\text { Presto }(\mathrm{D} ; \mathrm{c} /)\end{array}$ & $\begin{array}{l}\text { vl (2), a-vla, b, } \\
\text { fl (2), cor (2), } \\
\text { clno (2), timp }\end{array}$ & ok. 1800 & $\begin{array}{c}\text { Muz GR } \\
\text { V/36 (257) }\end{array}$ \\
\hline 30 & $\begin{array}{c}\text { Pleyel Ignace } \\
\text { (1757-1831) }\end{array}$ & $\begin{array}{l}\text { Symfonia C } \\
\text { (BenP 128) }\end{array}$ & $\begin{array}{l}\text { Allegro }(\mathrm{C} ; 4 / 4) \\
\text { Adagio con sordini } \\
(\mathrm{F} ; 3 / 4) \\
\text { Menuetto }(\mathrm{C} ; 3 / 4) \\
\text { Rondo. Allegro } \\
(\mathrm{C} ; 2 / 4)\end{array}$ & $\begin{array}{l}\text { vl (2), vla, } \\
\text { fl (2), cor (2), } \\
\operatorname{cl}(2), \text { org }\end{array}$ & $\begin{array}{c}\text { ok. } 1780 \\
\text { (rps zb.), } \\
\text { J. Ścigalski, } \\
\text { P. S. } \\
\text { Kinosowicz }\end{array}$ & $\begin{array}{c}\text { Muz GR } \\
\text { V/47 [5] } \\
(260)\end{array}$ \\
\hline 31 & Pleyel Ignace & $\begin{array}{l}\text { Symphonia ex } \\
\text { G-dur [BenP } \\
141]\end{array}$ & $\begin{array}{l}\text { Allegro }(\mathrm{G} ; 3 / 4) \\
\text { Adagio }(\mathrm{D} ; 4 / 4) \\
\text { Menuetto un poco } \\
\text { allegro }(\mathrm{G} ; 3 / 4) \\
\text { Allegro }(\mathrm{G} ; 2 / 4)\end{array}$ & $\begin{array}{l}\text { vl (2), vla (2), } \\
\text { vlc, b, ob (2), } \\
\text { cor (2) }\end{array}$ & $\begin{array}{l}\text { ok. } 1780, \\
\text { P. S. } \\
\text { Kinosowicz }\end{array}$ & $\begin{array}{c}\text { Muz GR } \\
\text { V/41 (261) }\end{array}$ \\
\hline 32 & $\begin{array}{l}\text { Pleyel Ignace } \\
\text { (J. Haydn ?) }\end{array}$ & $\begin{array}{l}\text { Sinfonia in F } \\
{[\text { BenP 136]; }} \\
{[\text { Hob I : F14] }}\end{array}$ & $\begin{array}{l}\text { Allegro assai } \\
(\mathrm{F} ; 4 / 4) \\
\text { Andante grazioso } \\
(\mathrm{B} ; 6 / 8) \\
\text { Menuetto. } \\
\text { Allegretto }(\mathrm{F} ; 3 / 4) \\
\text { Rondo }(\mathrm{F} ; 2 / 4)\end{array}$ & $\begin{array}{l}\text { vl (2), vla, b, } \\
\text { ob (2), fag (2), } \\
\text { timp }\end{array}$ & $\begin{array}{l}\text { 1791, } \\
\text { Bernard } \\
\text { Fritsch, } \\
\text { St. Ścigalski, } \\
\text { P. S. } \\
\text { Kinosowicz }\end{array}$ & $\begin{array}{c}\text { Muz GR } \\
\text { V/42 (262) }\end{array}$ \\
\hline 33 & Pleyel Ignace & $\begin{array}{l}\text { Sinfonia in } \mathrm{Cb} \\
{[\text { BenP 121] }}\end{array}$ & $\begin{array}{l}\text { Allegro molto } \\
(\mathrm{c} ; 4 / 4) \\
\text { Adagio }(\mathrm{F} ; 2 / 4) \\
\text { Minuetto }(\mathrm{C} ; 3 / 4) \\
\text { Finale. Presto } \\
(\mathrm{C} ; 4 / 4)\end{array}$ & $\begin{array}{l}\text { vl (2), a-vla, b, } \\
\text { ob (2), cor (2), } \\
\text { trb, timp }\end{array}$ & $\begin{array}{l}\text { ok. } 1791 \\
\text { (rps zb.) }\end{array}$ & $\begin{array}{c}\text { Muz GR } \\
\text { V/20 [3] } \\
(263)\end{array}$ \\
\hline
\end{tabular}




\begin{tabular}{|c|c|c|c|c|c|c|}
\hline & Kompozytor & Tytul & $\begin{array}{l}\text { Części } \\
\text { (tonacja } \\
\text { metrum) }\end{array}$ & Obsada & $\begin{array}{l}\text { Data, } \\
\text { kopista, } \\
\text { posesor }\end{array}$ & Sygnatura \\
\hline 34 & Pleyel Ignace & $\begin{array}{l}\text { [Symfonia B] } \\
{[\text { BenP 125] }}\end{array}$ & $\begin{array}{l}\text { Allegro }(\mathrm{B} ; 3 / 4) \\
\text { Andantino }(\mathrm{F} ; 2 / 4) \\
\text { Minuetto }(\mathrm{B} ; 3 / 4) \\
\text { Finale. Allegro } \\
(\mathrm{B} ; \mathrm{c} /)\end{array}$ & $\begin{array}{l}\text { vl (2), a-vla, b, } \\
\text { ob (2), cor (2), } \\
\text { trb, timp }\end{array}$ & $\begin{array}{l}\text { ok. } 1791 \\
\text { (rps zb.) }\end{array}$ & $\begin{array}{c}\text { Muz GR } \\
\text { V/20 [4] } \\
(264)\end{array}$ \\
\hline 35 & Pleyel Ignace & $\begin{array}{l}\text { Symfonia Es } \\
{[\text { BenP 144] }}\end{array}$ & $\begin{array}{l}\text { Allegro molto } \\
\text { (Es; 4/4) }\end{array}$ & $\begin{array}{l}\text { vlc } \\
\text { (zachowany) }\end{array}$ & ok. 1790 & $\begin{array}{c}\text { Muz GR } \\
\text { V/25 (265) }\end{array}$ \\
\hline 36 & $\begin{array}{c}\text { Stamitz, Carl } \\
(1745-1801)\end{array}$ & $\begin{array}{l}\text { [Symp]honia } \\
\text { in Dis }\end{array}$ & & $\begin{array}{l}\text { vl (2), a-vla, b, } \\
\text { fl (2), cor (2) }\end{array}$ & $\begin{array}{l}\text { ok. } 1830, \\
\text { S. Ścigalski, } \\
\text { k. tyt. } \\
\text { (zachowana) }\end{array}$ & $\begin{array}{c}\text { Muz GR I/98 } \\
\text { [2] (316) }\end{array}$ \\
\hline 37 & $\begin{array}{c}\text { Ścigalski } \\
\text { Franciszek } \\
(\mathbf{1 7 8 2 - 1 8 4 6 )}\end{array}$ & $\begin{array}{l}\text { Symphonia } \\
\text { in D }\end{array}$ & $\begin{array}{l}\text { Adagio maestoso } \\
(\mathrm{D} ; 3 / 4) \\
\text { Andante }(\mathrm{d} ; 2 / 4) \\
\text { Menuetto }(\mathrm{D} ; 3 / 4) \\
\text { Rondo (D; } 2 / 4)\end{array}$ & $\begin{array}{l}\text { vl (2) a-vla, b, } \\
\text { fl (2), cor (2), } \\
\operatorname{tr}(2), \operatorname{timp}\end{array}$ & $\begin{array}{l}\text { ok. } 1810, \\
\text { S. Ścigalski } \\
\text { P. S. } \\
\text { Kinosowicz }\end{array}$ & $\begin{array}{c}\text { Muz GR } \\
\text { V/45 (326) }\end{array}$ \\
\hline 38 & Anonim & Sinfonia $[$ Es] & $\begin{array}{l}\text { Allegro assai } \\
\text { (Es; 4/4) } \\
\text { Andante }(B ; 2 / 4) \\
\text { Presto (Es; 6/8) }\end{array}$ & $\begin{array}{l}\operatorname{vl}(2), \text { vla, b, } \\
\operatorname{cl}(2), \operatorname{cor}(2)\end{array}$ & $\begin{array}{l}\text { ok. } 1760 \text {, } \\
\text { J. Wo. } \\
\text { P. S. } \\
\text { Kinosowicz }\end{array}$ & $\begin{array}{c}\text { Muz GR } \\
\text { V/39 (604) }\end{array}$ \\
\hline 39 & Anonim & Symfonia D & \begin{tabular}{|l} 
Allegro molto \\
$(\mathrm{D} ; 4 / 4)$ \\
Andante affetuoso \\
$(\mathrm{G} ; 2 / 4)$ \\
Menuet $(\mathrm{D} ; 3 / 4)$ \\
Rondo. Allegro \\
moderato $(\mathrm{D} ; 2 / 4)$
\end{tabular} & $\begin{array}{l}\text { vl (2), vla, } \\
\text { fl (2) lub cl (2), } \\
\text { cor (2), org }\end{array}$ & $\begin{array}{l}\text { ok. } 1780 \\
\text { (rps zb.), } \\
\text { J. Ścigalski, } \\
\text { P. S. } \\
\text { Kinosowicz }\end{array}$ & $\begin{array}{c}\text { Muz GR } \\
\text { V/47 [4] } \\
(602)\end{array}$ \\
\hline 40 & Anonim & $\begin{array}{l}\text { [Symfonia Es] } \\
\text { Symphonia } \\
\text { in Dis }\end{array}$ & $\begin{array}{l}\text { Allegro (Es; } 4 / 4) \\
\text { Andante }(B ; 2 / 4) \\
\text { Menuet }(\text { Es; } 3 / 4) \\
\text { Rondo. Moderato } \\
(\text { Es; } 2 / 4)\end{array}$ & $\begin{array}{l}\text { vl (2), vla, } \\
\text { fl (2) lub cl (2), } \\
\text { cor (2), org; } \\
\text { vl (2), a-vla, b, } \\
\text { cl (2), cor (2) }\end{array}$ & $\begin{array}{l}\text { ok. } 1780 \\
\text { (rps zb.), } \\
\text { J. Ścigalski, } \\
\text { P. S. } \\
\text { Kinosowicz }\end{array}$ & $\begin{array}{c}\text { Muz GR } \\
\text { V/47 [2] } \\
(607) ; \\
\text { V/43 (606) }\end{array}$ \\
\hline 41 & $\begin{array}{c}\text { Gyrowetz } \\
\text { Adalbert } \\
(\mathbf{1 7 6 3 - 1 8 5 0 )}\end{array}$ & $\begin{array}{l}\text { Synfonia } \\
\text { Concertante } \\
\text { op. } 33 \text { [RicG } \\
\text { D8] }\end{array}$ & $\begin{array}{l}\text { Allegro con } \\
\text { spirito }(\mathrm{D} ; 4 / 4) \\
\text { Andantino }(\mathrm{G} ; 2 / 4) \\
\text { Rondo }(\mathrm{D} ; 2 / 4)\end{array}$ & $\begin{array}{l}\text { vl (2), vla, b, } \\
\text { fl (2), ob. (2), } \\
\text { cl (2), cor (2) }\end{array}$ & 1790 & $\begin{array}{c}\text { Muz GR } \\
\text { V/13 (211) }\end{array}$ \\
\hline
\end{tabular}




\begin{tabular}{|c|c|c|c|c|c|c|}
\hline & Kompozytor & Tytul & $\begin{array}{c}\text { Części } \\
\text { (tonacja } \\
\text { metrum) }\end{array}$ & Obsada & $\begin{array}{l}\text { Data, } \\
\text { kopista, } \\
\text { posesor }\end{array}$ & Sygnatura \\
\hline 42 & $\begin{array}{c}\text { Ziegenheim } \\
\text { Franz (18.sc) }\end{array}$ & $\begin{array}{l}\text { Concerto Ex } \\
\text { [Es] Corno } \\
\text { Principale }\end{array}$ & $\begin{array}{l}\text { Allegro (Es; 2/4) } \\
\text { Andante (Es; 2/4) } \\
\text { Allegro (Es; 2/4) }\end{array}$ & $\begin{array}{l}\text { cor solo, vl (2), } \\
\text { vla, b }\end{array}$ & $\begin{array}{l}\text { ok. 1780, } \\
\text { S. Ścigalski }\end{array}$ & $\begin{array}{c}\text { Muz GR } \\
\text { V/38 (379) }\end{array}$ \\
\hline 43 & Wurst (18/19) & $\begin{array}{l}\text { Ouverture. } \\
\text { Z Baletu } \\
\text { Rendez } \\
\text { komicznego }[\mathrm{D}]\end{array}$ & Andante $(\mathrm{D} ; 6 / 8)$ & tylko fl & $\begin{array}{l}\text { ok. } 1790 \text {, } \\
\text { C. M. }\end{array}$ & $\begin{array}{c}\text { Muz GR } \\
\text { V/29 (371) }\end{array}$ \\
\hline
\end{tabular}

Tabela 2. Duety instrumentalne

\begin{tabular}{|c|c|c|c|c|c|c|}
\hline & Kompozytor & Tytul & $\begin{array}{c}\text { Części } \\
\text { (tonacja metrum) }\end{array}$ & Obsada & $\begin{array}{c}\text { Data, } \\
\text { kopista, } \\
\text { posesor }\end{array}$ & Sygnatura \\
\hline 1 & $\begin{array}{c}\text { Bériot } \\
\text { Charles- } \\
\text { Auguste de } \\
\text { (1802-1870 }\end{array}$ & Duo $[\mathrm{d}, \mathrm{D}]$ & $\begin{array}{l}\text { Adagio maestoso } \\
(\mathrm{d} ; 4 / 4) \\
\text { Thema con } 5 \\
\text { variationi }(\mathrm{D} ; 3 / 4) \\
\text { Finale. Allegro ma } \\
\text { non troppo }(\mathrm{D} ; 6 / 8)\end{array}$ & vl, pf & $\begin{array}{c}1840, \\
\text { A. } \\
\text { Jaskowski }\end{array}$ & $\begin{array}{l}\text { Muz GR } \\
\text { V/2 (13) }\end{array}$ \\
\hline 2 & $\begin{array}{l}\text { Campagnoli } \\
\text { Bartolomeo } \\
(1751-1827)\end{array}$ & $\begin{array}{l}\text { Trios Thèmes } \\
\text { d'airs connus } \\
\text { variées pour } \\
\text { deux Violons, } \\
\text { op. } 7\end{array}$ & & $\mathrm{vl}(2)$ & $\begin{array}{l}\text { ok.1790 [?]; } \\
\text { druk: } \\
\text { Leipzig, } \\
\text { Breitkopf \& } \\
\text { Härtel }\end{array}$ & $\begin{array}{c}\text { Muz GR } \\
\text { V/34 (32) }\end{array}$ \\
\hline 3 & $\begin{array}{c}\text { Gravrand } \\
\text { Joseph } \\
\text { (1770-1847) }\end{array}$ & Duo [Es, c ?] & $\begin{array}{l}\text { Allegro moderato } \\
(\text { Es; } 4 / 4) \\
\text { Andante poco } \\
(B ; 4 / 4) \\
\text { Polacca moderato } \\
(\text { Es; } 3 / 4)\end{array}$ & $\mathrm{vl}(2)$ & $\begin{array}{l}\text { ok. } 1800 \text {, } \\
\text { P. Nierel } \\
\text { (rps zb.) }\end{array}$ & $\begin{array}{c}\text { Muz GR } \\
\text { V22 [1] } \\
(153)\end{array}$ \\
\hline 4 & $\begin{array}{l}\text { Gravrand } \\
\text { Joseph }\end{array}$ & Duo [B] & $\begin{array}{l}\text { Allegro }(\mathrm{B} ; 4 / 4) \\
\text { Andante romanze } \\
(\text { Es; } 3 / 8) \\
\text { Rondo. Allegro } \\
\text { non troppo }(\mathrm{B} ; 2 / 4)\end{array}$ & $\mathrm{vl}(2)$ & $\begin{array}{l}\text { ok. } 1800 \\
\text { (rps zb.) }\end{array}$ & $\begin{array}{c}\text { Muz GR } \\
\text { V22 [2] } \\
(154)\end{array}$ \\
\hline
\end{tabular}




\begin{tabular}{|c|c|c|c|c|c|c|}
\hline & Kompozytor & Tytuł & $\begin{array}{c}\text { Części } \\
\text { (tonacja metrum) }\end{array}$ & Obsada & $\begin{array}{l}\text { Data, } \\
\text { kopista, } \\
\text { posesor }\end{array}$ & Sygnatura \\
\hline 5 & $\begin{array}{l}\text { Kreubé } \\
\text { Charles- } \\
\text { Frédéric } \\
\text { (1777-1846) }\end{array}$ & Duetto [f] & $\begin{array}{l}\text { Allegro agitato } \\
\text { (f; } 4 / 4)\end{array}$ & $\operatorname{vl}(2)[?]$ & $\begin{array}{l}\text { ok. } 1800 \\
\text { (rps zb.) }\end{array}$ & $\begin{array}{c}\text { Muz GR } \\
\text { V22 [3] } \\
(216)\end{array}$ \\
\hline 6 & $\begin{array}{l}\text { Kreubé } \\
\text { Charles- } \\
\text { Frédéric }\end{array}$ & $\begin{array}{l}\text { Duet (Es-dur) } \\
\text { Wariacje }\end{array}$ & $\begin{array}{l}\text { Allegro moderato } \\
(\text { Es; } 4 / 4) \\
\text { Allegretto }(\text { Es; } 2 / 4) \\
\text { Thema con } \\
\text { variazioni. } \\
\text { Andante moderato } \\
(\mathrm{A} ; 2 / 4)\end{array}$ & $\operatorname{vl}(2)$ [?] & $\begin{array}{l}\text { ok. } 1800 \\
\text { (rps zb.) }\end{array}$ & $\begin{array}{c}\text { Muz GR } \\
\text { V22 [4] } \\
(217)\end{array}$ \\
\hline 7 & $\begin{array}{l}\text { Grosmann } \\
\text { Zygmunt } \\
\text { Stanislaw } \\
(\mathbf{1 7 8 6 - 1 8 5 0 )}\end{array}$ & [Duet C-dur] & $\begin{array}{l}\text { Allegro moderato } \\
(\mathrm{C} ; 4 / 4) \\
\text { Rondo. Allegro } \\
(\mathrm{C} ; 2 / 4)\end{array}$ & $\mathrm{vl}(2)$ & $\begin{array}{l}\text { au. ok. } 1815 \\
\text { (rps zb.); } \\
\text { dedykacja: } \\
\text { Philip de } \\
\text { Batthyani }\end{array}$ & $\begin{array}{c}\text { Muz GR } \\
\text { V/1 [1] (165) }\end{array}$ \\
\hline 8 & $\begin{array}{l}\text { Grosman } \\
\text { Zygmunt } \\
\text { Stanisław }\end{array}$ & [Duet G-dur] & $\begin{array}{l}\text { Allegro moderato } \\
(\mathrm{G} ; \mathrm{c} /) \\
\text { Andante }(\mathrm{G} ; 2 / 4) \\
\text { Allegretto }(\mathrm{G} ; 6 / 8)\end{array}$ & $\mathrm{vl}(2)$ & $\begin{array}{l}\text { au. ok. 1815, } \\
\text { (rps zb.) }\end{array}$ & $\begin{array}{c}\text { Muz GR } \\
\text { V/1 [2] (166) }\end{array}$ \\
\hline 9 & $\begin{array}{l}\text { Grosman } \\
\text { Zygmunt } \\
\text { Stanisław }\end{array}$ & [Duet B-dur] & $\begin{array}{l}\text { Allegro moderato } \\
(\mathrm{B} ; \mathrm{c} /) \\
\text { Rondo. Allegretto } \\
(\mathrm{B} ; 2 / 4)\end{array}$ & $\mathrm{vl}(2)$ & $\begin{array}{l}\text { au. ok. } 1815 \\
\text { (rps zb.) }\end{array}$ & $\begin{array}{c}\text { Muz GR } \\
\text { V/1 [3] (167) }\end{array}$ \\
\hline 10 & $\begin{array}{c}\text { Pleyel Ignace } \\
\text { (1757-1831) }\end{array}$ & $\begin{array}{l}\text { [Duet G-dur] } \\
\text { (BenP 535) }\end{array}$ & $\begin{array}{l}\text { Allegro (G; 4/4) } \\
\text { Romanza }(\mathrm{g} ; \mathrm{c} /) \\
\text { Rondo. Allegro } \\
(\mathrm{G} ; 4 / 4)\end{array}$ & $\mathrm{vl}(2)$ & $\begin{array}{l}\text { ok. } 1810 \\
\text { (rps zb.) }\end{array}$ & $\begin{array}{c}\text { Muz GR } \\
\text { V/3 [1] (266) }\end{array}$ \\
\hline 11 & Pleyel Ignace & $\begin{array}{l}\text { [Duet B-dur] } \\
\text { (BenP 536) }\end{array}$ & $\begin{array}{l}\text { Allegro }(\mathrm{B} ; 6 / 8) \\
\text { Andante con moto } \\
(\text { Es; } 3 / 4) \\
\text { Rondo. Allegro } \\
(\mathrm{B} ; 2 / 4)\end{array}$ & $\mathrm{vl}(2)$ & $\begin{array}{l}\text { ok. } 1810 \\
\text { (rps zb.) }\end{array}$ & $\begin{array}{c}\text { Muz GR } \\
\text { V/3 [2] (267) }\end{array}$ \\
\hline 12 & Pleyel Ignace & $\begin{array}{l}\text { [Duet D-dur] } \\
\text { (BenP 537) }\end{array}$ & $\begin{array}{l}\text { Allegro spirituoso } \\
(\mathrm{D} ; 3 / 4) \\
\text { Andante }(\mathrm{A} ; \mathrm{c} /) \\
\text { Polonese }(\mathrm{D} ; 3 / 4)\end{array}$ & $\operatorname{vl}(2)$ & $\begin{array}{l}\text { ok. } 1810 \\
\text { (rps zb.) }\end{array}$ & $\begin{array}{c}\text { Muz GR } \\
\text { V/3 [3] (268) }\end{array}$ \\
\hline
\end{tabular}


Tabela 3. Tańce

\begin{tabular}{|c|c|l|l|l|c|c|}
\hline & Kompozytor & Tytul & $\begin{array}{c}\text { Części } \\
\text { (tonacja metrum) }\end{array}$ & Obsada & $\begin{array}{c}\text { Data, } \\
\text { kopista, } \\
\text { posesor }\end{array}$ & Sygnatura \\
\hline 1 & Anonim & [polonezy - 12] $]$ & & tylko cl & ok. 1800 & $\begin{array}{c}\text { Muz GR } \\
\text { V/30 (599) }\end{array}$ \\
\hline 2 & Anonim & Walc Anglese & $\begin{array}{l}\text { C; 3/4 } \\
\text { F; 2/4 }\end{array}$ & tylko vl 1 & $\begin{array}{c}\text { ok. 1790, } \\
\text { Posesor CM }\end{array}$ & $\begin{array}{c}\text { Muz GR } \\
\text { V/27 (613) }\end{array}$ \\
\hline 3 & Anonim & $\begin{array}{l}{[\text { Taniec ?] }} \\
\text { Walc ? } \\
\text { Mazur } \\
4 \text { Contredanse }\end{array}$ & & $?$ & ok. 1790 & $\begin{array}{c}\text { Muz GR } \\
\text { V/32 (614) }\end{array}$ \\
\hline 4 & Anonim & $\begin{array}{l}\text { Polonez } \\
{[\text { Polonez }]} \\
\text { Mazur } \\
\text { Walc }[\text { Walc }] \\
{[\text { Air] }}\end{array}$ & & fl2 & ok. 1790 & $\begin{array}{c}\text { Muz GR } \\
\text { V/26 (615) }\end{array}$ \\
\hline
\end{tabular}

BIBLIOGRAFIA

Bula, Karol. „Bériot Charles Auguste de”. Dziębowska, t. A-B, ss. 284.

Brzezińska, Barbara. „Abel Carl Friedrich”. Dziębowska, t. A-B, ss. 2-3.

Chmara-Żaczkiewicz, Barbara. „Ścigalski Franciszek”. Dziębowska, t. Sm-Ś, ss. 302-303.

Chwedczuk, Zofia. „Gossec, François-Joseph”. Dziębowska, t. E-F-G, ss. 403-405.

Duszyk, Krystyna. „Pietrowski Karol”. Dziębowska, t. Pe-R, ss. 106-107.

Dziębowska, Elżbieta, redaktor. Encyklopedia muzyczna PWM. Część biograficzna. Polskie Wydawnictwo Muzyczne, 1979-2012. 12 tomów.

„Habel Antoni”. Dziębowska, t. H-I-J, ss. 4.

Idaszak, Danuta. Grodzisk Wielkopolski. Katalog tematyczny muzykaliów. Musica Iagellonica, 1993. Idaszak, Danuta. „Dankowski, Danek, Adalbertus, Wojciech”. Dziębowska, t. C-D, ss. 339.

Mądry, Alina. Historia Muzyki Polskiej, t. 3: Barok, cz. 2: 1697-1795. Muzyka religijna i jej barokowy modus operandi. Sutkowski Edition Warsaw, 2013.

Répertoire International des Sources Musicales. RISM database, opac.rism.info. Dostęp 30.03.2021.

Smolarek, Dariusz. „Kompozytorzy muzyki instrumentalnej zachowanej w archiwum opactwa cystersów w Krakowie-Mogile. Problem atrybucji”. Roczniki Teologiczne, t. 63, nr 13, Muzykologia, 2016, ss. 173-202.

Stróżyńska, Beata. Broszura CD w Jasnogórska Muzyka Dawna. Musica Claromontana 40, Acte Préalable, 2017, 0185. 
Stróżyńska, Beata. Symfonia w XVIII-wiecznej Polsce. Teoria, repertuar i cechy stylistyczne. Wydawnictwo Akademii Muzycznej im. Grażyny i Kiejstuta Bacewiczów w Łodzi, 2015.

Československý hudebni slovník osob a institucí, ed. Gracian Černušák et al., www.ceskyhudebnislovnik.cz/slovnik/index.php?option=com_mdictionary\&task=record.re cord_detail\&id=1000622. Dostęp 31.03.2021.

\author{
MUZYKA INSTRUMENTALNA KAPELI KOŚCIOŁA FARNEGO \\ PW. ŚW. JADWIGI ŚLĄSKIEJ W GRODZISKU WIELKOPOLSKIM
}

\title{
Streszczenie
}

Zachowane muzykalia osiemnastowiecznych kościelnych kapel muzycznych wskazują, że w ich repertuarze znajdowały się nie tylko dzieła sakralne, ale również instrumentalne. Bardzo popularnym gatunkiem były utwory zwane symfonią. Jednym z takich zasobów z utworami instrumentalnymi są nuty po kapeli muzycznej parafii św. Jadwigi Śląskiej w Grodzisku Wielkopolskim.

Autorami zachowanych symfonii byli zagraniczni kompozytorzy z kręgu szkoły mannheimskiej oraz dojrzałego kręgu klasycznego. Dla rodzimych twórców stanowili oni wzór tworzenia utworów instrumentalnych. Symfonie, jak to było w ówczesnym zwyczaju, były wykonywane również podczas liturgii. Można więc mówić o zjawisku zwanym symfonia kościelna.

Słowa kluczowe: XVIII-wieczna symfonia; polscy twórcy symfonii; muzyka kościelna; Grodzisk Wielkopolski.

\section{THE INSTRUMENTAL MUSIC OF THE PARISH CHURCH BAND OF ST. JADWIGA ŚLASKA IN GRODZISK WIELKOPOLSKI}

\section{S u m m a r y}

The preserved musical pieces of 18th-century church music bands indicate that their repertoire included not only sacred works, but also instrumental pieces. A very popular genre were those called symphonies. One such resource for instrumental works are the notes from the music band of the parish of St. Jadwiga Śląska in Grodzisk Wielkopolski.

The authors of the extant symphonies were foreign composers from the Mannheim school, as well as "mature classical" circles. For native Polish composers, they were a model for the creation of instrumental pieces. Symphonies, as was the custom of the time, were also performed during the liturgy. Thus, we can talk of a phenomenon called the church symphony.

Keywords: 18th-century symphony; Polish symphony composers; church music; Grodzisk Wielkopolski. 